\title{
Programas de orientação profissional: modelos para desenvolvimento de políticas públicas no Brasil
}

\section{Vocational Guidance Programs: models for development of public policies in Brazil}

\author{
Egypcialinda Camargo Suzuki (orcid.org/0000-0002-3561-0867)' \\ Gislei Mocelin Polli (orcid.org/0000-0001-7254-7441)²
}

\begin{abstract}
Resumo
Programas de Orientação Profissional (OP) são de vital importância na vida dos jovens que concluem o ensino médio, no entanto, apenas uma parcela dos estudantes tem acesso a esse serviço. Na ausência de leis que regulamentem a OP em escolas públicas no Brasil, este estudo pretendeu identificar na literatura artigos que apresentam Programas de Orientação Profissional que possam ser utilizados como contribuição para a construção de políticas públicas. Para tanto, foi realizado um estudo bibliográfico, sendo selecionados oito artigos que apresentavam Programas de Orientação Profissional a partir de diferentes abordagens. Foram percebidas algumas características que favoreceram a efetividade das propostas. As equipes de trabalho eram formadas por um mínimo de dois até cinco pesquisadores. Os estudos indicam que a inserção de Programas de Orientação Profissional ao longo do Ensino Médio, incluindo a fase do pré-vestibular e Ensino Profissionalizante, traz resultados efetivos.
\end{abstract}

Palavras-chave: Orientação profissional. Programas. Políticas públicas.

\begin{abstract}
Vocational Guidance Programs (OP) are vitally importance in the lives of young people who complete high school, however, only a portion of students have access to this service. In the absence of laws that regulate OP in public that can be used as a contribution to the construction of public policies. To this end, a bibliographic study was effective results.

\footnotetext{
${ }^{1}$ Universidade Tuiuti do Paraná, Curitiba, Brasil. E-mail: egypcialindasuzuki@hotmail.com.

${ }^{2}$ Universidade Tuiuti do Paraná, Curitiba, Brasil. E-mail: gismocelin@gmail.com.
} schools in Brazil, this study aimed to identify in the literature articles that present Vocational Guidance Programs conducted and eight articles were selected that presented Vocational Guidance Programs from different approaches. Some characteristics that favored the effectiveness of the proposals were perceived. The work teams consisted of a minimum of two to five researchers. Studies indicate that the insertion of Vocational Guidance Programs throughout High School, including the pre-university entrance exam and Professionalizing Education phase, brings 
Keywords: Vocational Guidance. Programs. Public policies.

Os avanços tecnológicos e o acesso à informação geraram grandes mudanças na demanda e acesso à Educação nas ultimas décadas do século XX e início do século XXI. Os profissionais têm buscado trabalhar conjuntamente e a interdisciplinaridade e multidisciplinaridade dissolvem as fronteiras entre as diferentes profissões. As alternativas de atuação profissional se diversificam e a escolha de uma profissão torna-se mais do que possível, torna-se imprescindível, porém a diversidade de possibilidades leva os jovens a se questionarem sobre qual caminho seguir.

Depois da década de 1990, houve grandes mudanças no ensino superior no Brasil, tendo havido entre os anos de 2000 a 2011 um aumento de $114 \%$ do número de vagas ofertadas nas universidades. Além disso, políticas públicas educacionais, como o programa Universidade para Todos (Prouni), o Programa de Apoio a Planos de Reestruturação e Expansão das Universidades Federais Brasileiras (Reuni), a Lei de cotas raciais, entre outros, tornaram o acesso ao ensino superior mais democrático (Silva \& Bardagi, 2016).

Embora o acesso à educação superior tenha sido ampliado em todo o Brasil para os diferentes estratos sociais, sabe-se que não está disponível para toda a população. Do mesmo modo, nem todos os jovens que concluem o ensino médio buscam se estabelecer profissionalmente por meio de uma formação superior, buscando, muitas vezes, formações alternativas, como cursos técnicos, inserção imediata no mercado de trabalho ou ainda empreendedorismo. De todo modo, o período de conclusão do ensino médio é crítico para uma parcela importante de jovens que precisam fazer uma escolha que terá reflexos por toda sua vida profissional; nesse período, a Orientação Profissional (OP) pode ser de grande valia.

Orientação Profissional, para Melo-Silva, Lassance e Soares (2004), é o auxílio psicológico concedido ao indivíduo com o objetivo de sanar questões profissionais. Trata-se de uma prática na maior parte das vezes direcionada para estudantes que ambicionam chegar a uma profissão por meio de curso superior. O desenvolvimento da OP no campo da Psicologia esteve ligado à busca do aumento de eficiência nas indústrias, na busca de 
identificar pessoas aptas a desenvolver determinadas atividades. Diversas epistemologias embasaram seu desenvolvimento teórico e prático, tendo início nos Estados Unidos e Europa e posteriormente sendo disseminada por todo o mundo. Seu surgimento e desenvolvimento acompanharam as mudanças que foram ocorrendo no campo de recursos humanos e de gestão de pessoas e, nos dias de hoje, busca atender diferentes tipos de demanda (Fiorini, Bardagi \& Silva, 2016).

Atualmente, a OP abarca uma variedade de ações realizadas para auxiliar as pessoas em diferentes momentos de suas vidas profissionais, como no fim do ensino médio, quando estão passando por uma fase de desemprego, após a aposentadoria, no caso de mudança de curso superior, entre outros (Bonadiman, Scaff, Bardagi \& Luna, 2016). Há uma grande diversidade no formato dos programas de OP oferecidos, o que gera dúvidas sobre sua efetividade. Essa diversidade ocorre pela utilização de perspectivas teóricas diferenciadas e pelo uso de distintas técnicas, o que dificulta a comparação entre os programas (Ambiel, Barros, Pereira, Tofoli \& Bacan, 2017). Nessa diversidade de cenários, torna-se importante conhecer os programas de OP que vêm sendo oferecidos, tornando mais conhecidas as práticas adotadas pelos profissionais da área como forma de beneficiar a população diretamente interessada.

Para os jovens que podem arcar com os custos da rede privada, há muitos profissionais que oferecem OP em consultórios particulares, mas para aqueles que não podem arcar com um atendimento individualizado são criadas algumas alternativas como forma de preencher uma lacuna que o setor público não tem privilegiado. Alguns programas oferecidos por institutos de pesquisas e universidades são oferecidos à população em geral, geralmente sem custos ou a custos baixos, se comparados ao serviço privado. Mesmo assim o Brasil carece de políticas públicas voltadas à orientação profissional para jovens que concluem o ensino médio na rede pública de ensino.

Segundo Moura (2014), o processo de OP voltado aos jovens de escolas públicas tem tido dificuldade em avançar. Para o autor, devem-se pensar adaptações das metodologias de OP utilizadas no sistema privado, para atender esses jovens de maneira objetiva, gerando 
suporte na construção de projetos de vida e auxiliando na sua inserção social e profissional. Essa efetivação pode ocorrer por meio de políticas públicas de inclusão social.

Para Cunha e Cunha (2008), as políticas públicas têm sido formuladas como resposta do Estado às demandas da sociedade, sendo a representação da intenção pública de um determinado contexto social, temporal e cultural. Os autores reafirmam que a política social é um tipo de política pública que expressa um conjunto de paradigmas de "caráter permanente e abrangente que orientam a atuação do poder público em uma determinada área" (Cunha \& Cunha, 2008, p. 12).

Políticas públicas podem ser compreendidas como um conjunto de normas que indicam práticas e dão respaldo aos direitos dos cidadãos, em todos os graus e áreas da sociedade. De qualquer forma, estas devem ser fundamentadas nos princípios da igualdade e da equidade, difundindo o sentido de justiça social. Por meio das políticas públicas, os bens e serviços sociais são disseminados, remanejados, de forma a afiançar o direito social e acolher às demandas da sociedade (Silveira, Cobalchini, Menz, Valle \& Barbarini, 2007).

A lei que rege as diretrizes educacionais, Lei de Diretrizes de Bases (LDB, Lei n. 9.394, 1996), é responsável por determinar as bases para a elaboração das políticas públicas relacionadas à educação, mas não aborda diretamente a OP. O texto original da Lei de Diretrizes e Bases da Educação Nacional (LDben, Lei n. 4.024/61) não faz menção ao termo Orientação Profissional. O mesmo foi verificado em relação à legislação posterior (Lei n. 5.692/71. A LDB (Lei n. 9.394/96) art. 27, inc. III, se refere à orientação para o trabalho, mas não à orientação profissional. Há alguns projetos de lei que visam alterar a LDB incluindo a OP em escolas públicas, mas, atualmente, nenhum dos projetos concluídos foi aprovado, ainda que alguns estejam em trâmite.

Na ausência de políticas públicas de Orientação Profissional no Brasil, e ao identificar a ausência de leis que regulamentem tais práticas; e ainda considerando que projetos de lei, que buscam incluir a orientação profissional nas escolas de Ensino Médio, estão atualmente em trâmite ou arquivados; buscou-se identificar na literatura artigos que apresentam modelos de Programas de Orientação Profissional que possam ser utilizados como 
contribuição para a construção de políticas públicas que possam contar com maior chance de êxito.

\section{Método}

Trata-se de um estudo bibliográfico em que foram identificados na literatura artigos que apresentam Programas de Orientação Profissional para identificar modelos que possam contribuir na elaboração de políticas públicas de Orientação Profissional. Buscou-se identificar intervenções realizadas no Brasil, já que o objetivo é contribuir com a construção de políticas públicas de OP nacionais, e variações culturais poderiam interferir no sucesso dos programas. Desse modo, privilegiou-se a busca em bases de dados nacionais.

Os artigos selecionados apresentavam modelos de Programas de Orientação Profissional a partir de diferentes abordagens e em varias regiões do Brasil, mas devido ao reduzido número de intervenções relatadas no Brasil, optou-se por analisar também dois artigos que descrevem programas desenvolvidos em Portugal e que foram publicados no Brasil.

\section{Procedimento}

Para coleta de dados, foram selecionadas as bases de dados Google Acadêmico e SciELO, sendo utilizadas palavras-chave para busca em português os temos "Orientação Profissional" e "Programas de Orientação Profissional". Foram considerados artigos publicados após o ano 2000, Retomando a pesquisa inicial 363 resultados. Depois da exclusão dos artigos repetidos e produções como livros, teses e dissertações, restaram 276 artigos. Após a leitura do título dos artigos, foram selecionados 67 que poderiam apresentar Programas de Orientação Profissional. Por meio da leitura do resumo e do método, foram selecionados oito artigos que relatam a aplicação de Programas de Orientação Profissional. 
A pesquisa foi realizada entre os meses de março e maio de 2016. No mês de outubro de 2018 , a pesquisa foi refeita para inclusão de novos artigos; no entanto, não foram encontrados novos trabalhos que apresentassem descrições de programas de OP, de modo que a análise dos oito artigos iniciais foi mantida. A Figura 1 indica os passos seguidos para realização da coleta de dados.

Figura 1. Fluxograma do processo de busca e seleção de artigos

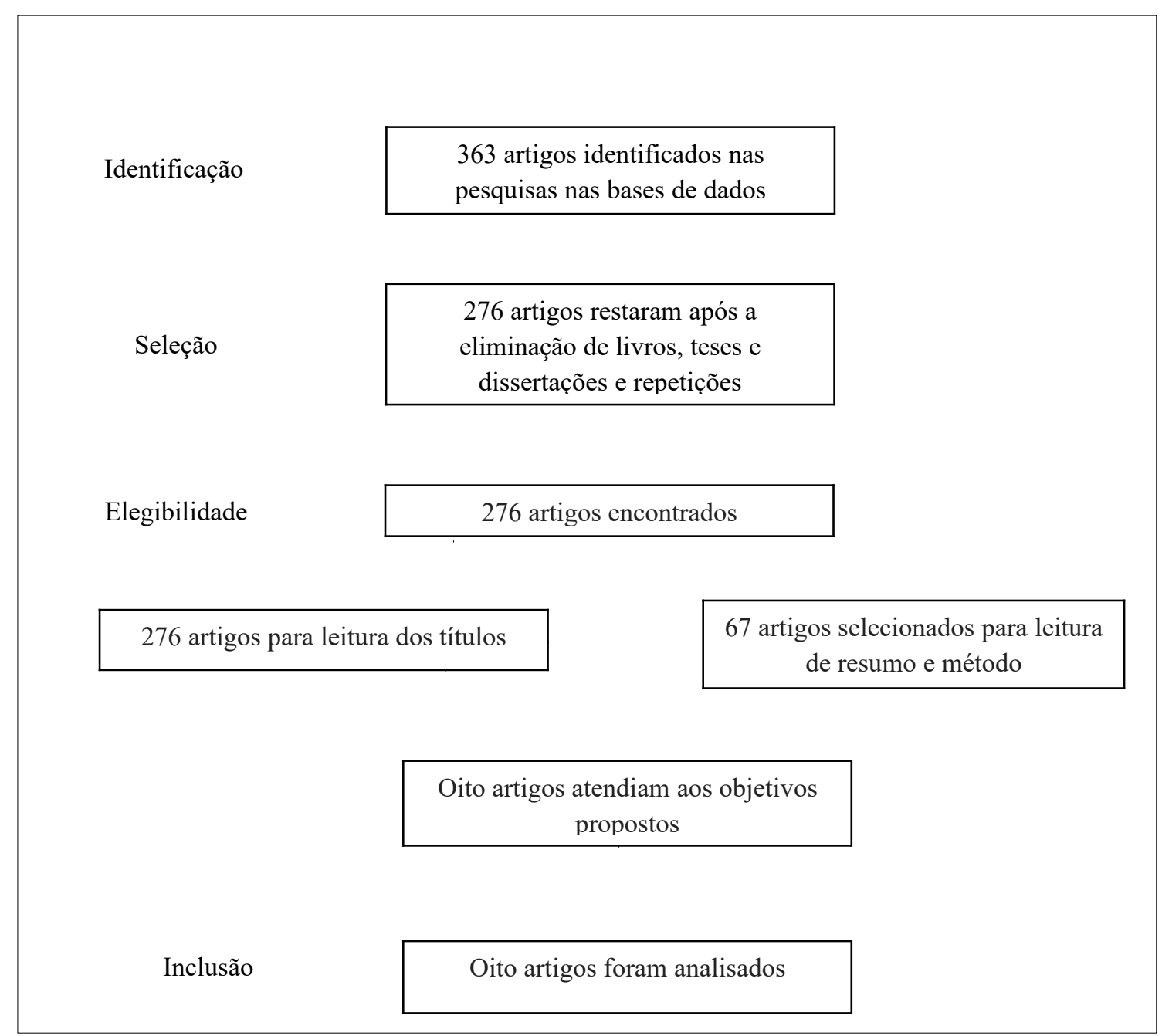

Fonte: Elaborada pelas autoras.

\section{Análise de dados}


Os dados oriundos da pesquisa bibliográfica foram agrupados de acordo com a proposta apresentada. Os artigos foram analisados e os seguintes itens foram classificados:

1. Título;

2. Ano de publicação;

3. Periódico - nome do periódico em que o artigo foi publicado;

4. Autores;

5. Resumo;

6. Palavras-chave;

7. Número de estudantes - que participaram das intervenções descritas;

8. Local - abrange cidades e universidades onde as intervenções foram realizadas;

9. Origem dos estudantes;

10. Objetivos;

11. Técnicas utilizadas - métodos utilizados para intervenção em OP;

12. Resultados alcançados.

\section{Resultados}

Após seleção e leitura dos artigos, eles foram agrupados e organizados para facilitar a compreensão dos resultados. Inicialmente, a descrição dos artigos pode ser observada no Quadro 1, em seguida cada artigo é descrito, detalhando os procedimentos utilizados pelos autores em cada um dos programas analisados.

Quadro 1. Artigos que descrevem programas de OP

\begin{tabular}{lcccc}
\hline \multicolumn{1}{c}{ Título } & Ano & Periódico & Participantes & Técnicas \\
\hline N1 - Orientação & 2007 & Psicologia & 127 & Psicodrama \\
profissional em & & Ciência e & estudantes & \\
contexto coletivo: uma & & Profissão & & \\
experiência em pré- & & & & \\
vestibular popular & & & & \\
\end{tabular}




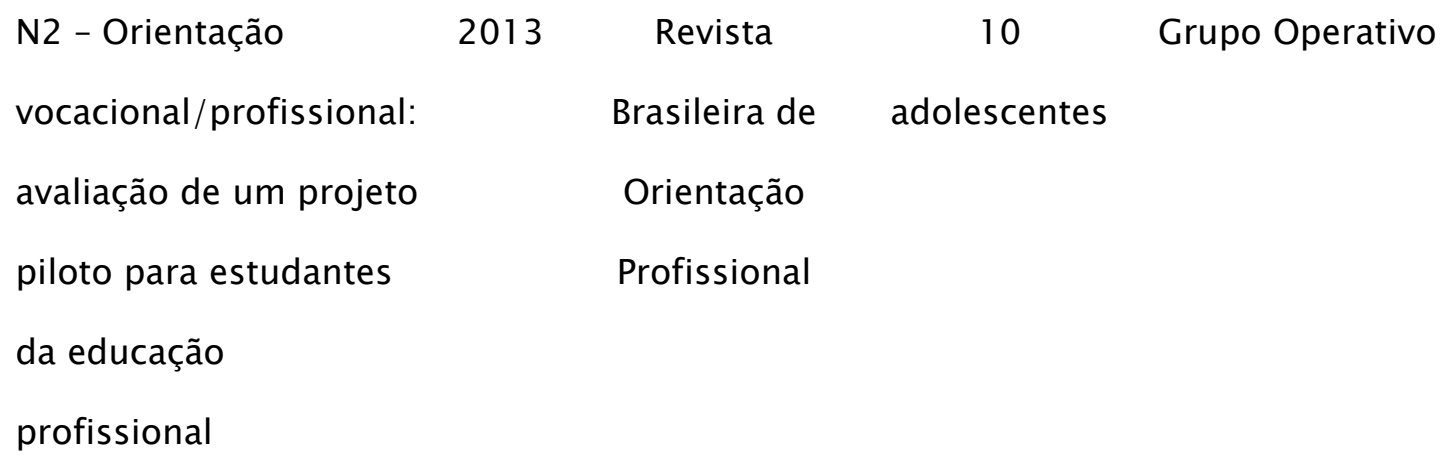

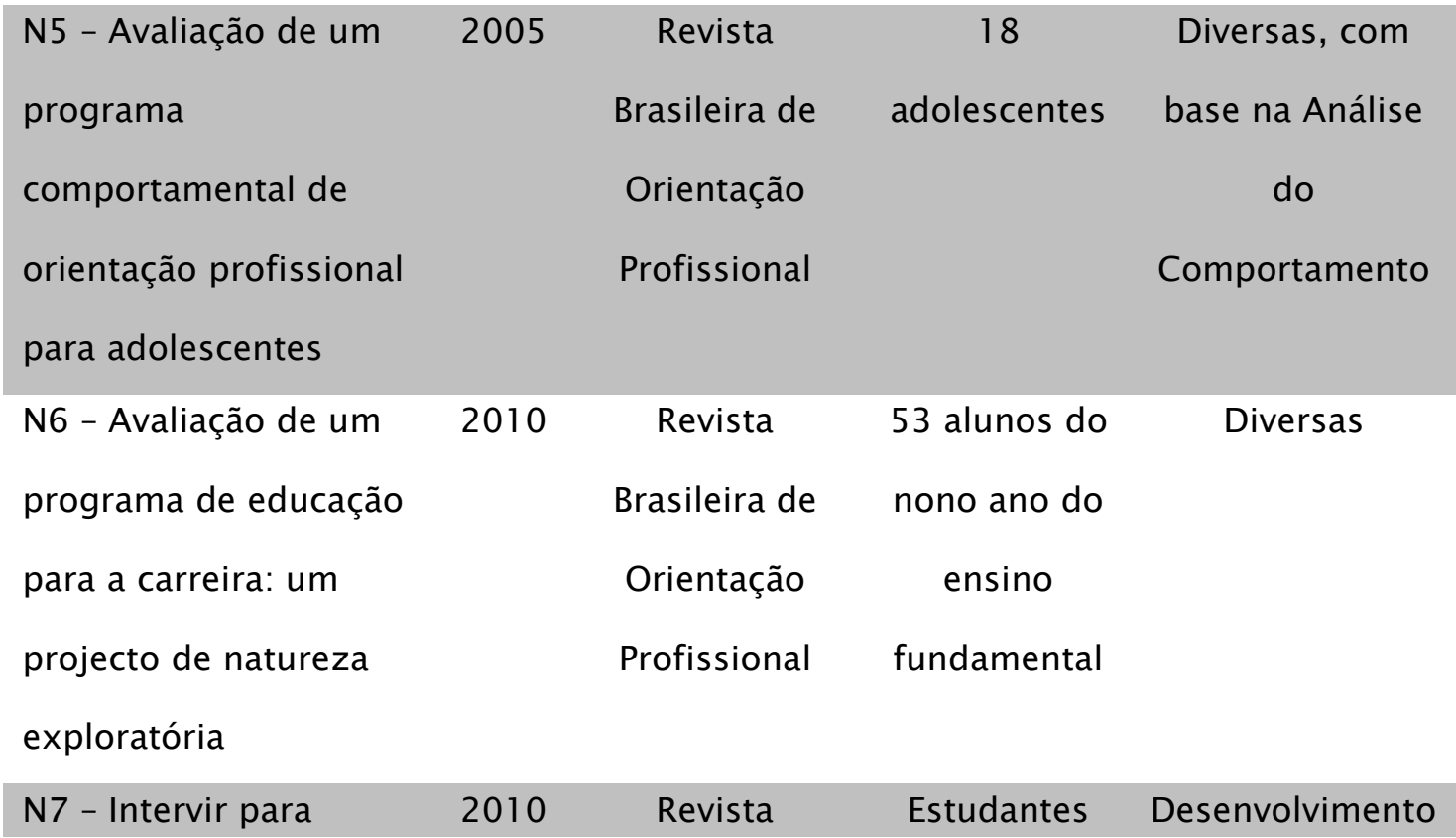




\begin{tabular}{|c|c|c|c|c|}
\hline $\begin{array}{l}\text { ajudar e ajudar para } \\
\text { construir: um modelo } \\
\text { de intervenção } \\
\text { psicológica com } \\
\text { estudantes do ensino } \\
\text { superior }\end{array}$ & & $\begin{array}{l}\text { Brasileira de } \\
\text { Orientação } \\
\text { Profissional }\end{array}$ & $\begin{array}{c}\text { do ensino } \\
\text { superior (N } \\
\text { não } \\
\text { informado) }\end{array}$ & de carreira \\
\hline $\begin{array}{l}\text { N8 - Oficina de } \\
\text { orientação profissional } \\
\text { em uma escola pública: } \\
\text { uma abordagem } \\
\text { Psicossocial }\end{array}$ & 2009 & $\begin{array}{l}\text { Psicologia: } \\
\text { Ciência e } \\
\text { Profissão }\end{array}$ & $\begin{array}{c}11 \\
\text { estudantes } \\
\text { do terceiro } \\
\text { ano do } \\
\text { ensino médio }\end{array}$ & Diversas \\
\hline
\end{tabular}

Fonte: Elaborado pelas autoras.

No artigo N1, Soares, Krawulski, Dias e D'Avila (2007) relatam uma atividade de Orientação Profissional realizada em um cursinho pré-vestibular popular da Universidade Federal de Santa Catarina com 127 estudantes reunidos em um grande grupo. As atividades foram realizadas com base em técnicas do psicodrama, com reuniões e debates grupais e a produção de cartazes, tendo como tema o processo de escolha do curso superior. O objetivo era uma maior expressão de sentimentos, identificação de objetivos e melhor integração, pelo fortalecimento do grupo e individualmente.

Em N2, Oliveira e Neiva (2013) apresentam o trabalho que se refere à avaliação de um projeto de Orientação Vocacional/Profissional desenvolvido com um grupo de 10 adolescentes com idades entre 16 e 18 anos que estavam cursando o penúltimo período de curso técnico de nível médio em uma instituição pública de educação profissional. Esse projeto visou facilitar o desenvolvimento vocacional dos estudantes e a construção de seus projetos profissionais. Foram realizados nove encontros em grupo, utilizando instrumentos e técnicas de grupo operativo para a orientação profissional. O projeto foi avaliado por meio da Escala de Maturidade para a Escolha Profissional e os resultados apontaram um aumento no nível de maturidade, observado no fim da intervenção. 
No artigo N3, Tetu, Domingues, Chiochetta e Veloso (2011) desenvolveram um trabalho como atividade de Estágio Profissionalizante de Psicologia, numa instituição da rede particular de ensino de Curitiba, com 12 estudantes do terceiro ano do ensino médio. O processo de Orientação Profissional ocorreu em nove encontros, com uma sessão semanal de noventa minutos. Foram utilizados instrumentos e técnicas como: entrevistas preliminares, dinâmicas de integração, testes e atividades de autoconhecimento, atividades relacionadas ao conhecimento das profissões envolvendo pesquisas dos próprios estudantes. No fim, foram revistas as expectativas manifestadas pelos participantes na entrevista preliminar e constatou-se que a maioria dos estudantes conseguiu escolher ou confirmar o curso para realizar o vestibular.

Em N4, Moura e Silveira (2002) descrevem o atendimento de um grupo em Orientação Profissional, segundo o enfoque da Análise do Comportamento. Esse programa ocorreu na clínica psicológica da Universidade Estadual de Londrina. Os autores avaliaram as mudanças ocorridas no comportamento dos adolescentes quanto à escolha profissional. Participaram da intervenção 10 adolescentes, de ambos os sexos, com idades entre 15 e 19 anos, alunos do ensino médio. O programa constou de nove sessões semanais para discussão do problema vocacional, focalizadas no desenvolvimento de autoconhecimento e conhecimento das profissões, por meio de entrevistas preliminares, dinâmicas de integração, testes e atividades de autoconhecimento e atividades relacionadas ao conhecimento das profissões - todas as atividades envolvendo pesquisas dos próprios orientandos. Na avaliação final, os resultados mostraram que $50 \%$ dos adolescentes conseguiram efetivar a escolha profissional e os outros $50 \%$ avançaram quanto aos critérios pessoais de seleção profissional, indicando que o modelo parece efetivo e necessita ser aprimorado para alcançar as necessidades de todos os adolescentes que procuram pelo programa.

No artigo N5, os autores Moura, Sampaio, Gemelli, Rodrigues e Menezes (2005) relatam a implantação de um programa de Orientação Profissional, segundo a Análise do Comportamento, para a solução do problema de escolha profissional. O programa, na Universidade Estadual de Londrina, constou de três etapas: entrevista, orientação em oito 
sessões e avaliação pós-orientação, focalizadas no desenvolvimento do autoconhecimento e do conhecimento das profissões. Os resultados mostraram que o programa com enfoque behaviorista propiciou melhora na maturidade para escolha e nas habilidades de tomada de decisão. Os autores concluíram que o modelo proposto mostrou-se efetivo para auxiliar adolescentes a avançarem em seu processo de decisão profissional.

No artigo N6, os pesquisadores Teixeira e Calado (2010) examinaram os resultados de um programa de educação para a carreira com 53 alunos, estudantes do nono ano do ensino regular de duas escolas do Alentejo, em Portugal. O programa envolveu 12 sessões, que incluíram a identificação do problema da escolha, considerando a fundamentação teórica, objetivos, estratégias, procedimentos e os resultados. Na conclusão, observou-se a necessidade de que práticas educativas da Orientação Profissional tenham uma natureza abrangente, para possibilitarem o desenvolvimento de competências vocacionais, promoção do sucesso acadêmico e o bem-estar na comunidade educativa.

No artigo N7, Lima e Fraga (2010) apresentaram um modelo de intervenção psicológica que se fundamenta na abordagem do desenvolvimento de carreira, contribuindo para a construção de caminhos de vida por meio dos diferentes papéis que o indivíduo desempenha. Tendo como ponto de partida a demanda de estudantes do ensino superior da Universidade de Lisboa, Portugal, que solicitaram ajuda num serviço de aconselhamento, analisaram diferentes tipos de solicitação em aconselhamento e gestão de carreira, ponderando como os indivíduos interpretam e representam as tarefas que determinado contexto Ihes coloca, que significado Ihes dá e como integram essas representações na sua história e na sua construção pessoal da carreira. Com base nessa análise, os autores enfatizaram a contribuição do modelo de intervenção em aconselhamento de carreira, pela orientação psicológica, para a tomada de decisão.

No artigo N8, Souza, Menandro, Bertollo e Rolke (2009) relatam uma intervenção de orientação profissional, realizada em uma escola pública de ensino médio, com 11 estudantes do terceiro ano (17 a 20 anos de idade). A oficina foi conduzida por meio de oito encontros semanais com duração de duas horas cada e partiu de um enfoque psicossocial, com base em uma avaliação crítica da sociedade e do trabalho e com o objetivo de ampliar a 
consciência dos indivíduos sobre o contexto escolar, familiar e de trabalho, favorecendo a atitude de participação mais ativa na escolha profissional. Os procedimentos utilizados foram técnicas de grupo e questionários abertos, com enfoque qualitativo, criado para a intervenção. Debateram com os participantes sobre o cotidiano escolar e as ideias sobre o sucesso pessoal. Foram apresentadas e discutidas informações objetivas sobre cursos e profissões, envolvendo os estudantes em uma atividade de pesquisa sobre profissões, realizada por meio de entrevistas. No fim da intervenção, os estudantes relataram maior segurança em relação aos planos de futuro e à escolha profissional e avaliaram positivamente a oficina.

\section{Pontos convergentes entre as experiências}

Entre os programas analisados, foram percebidas algumas características comuns que favoreceram a efetividade das propostas, as quais podem ser consideradas relevantes no momento de planejar e implementar políticas públicas de OP.

A partir da pesquisa realizada, identificou-se que os pesquisadores que desenvolveram os oitos Programas de Orientação Profissional são mestres e doutores em Psicologia, no Brasil e em Portugal. As equipes de trabalho eram formadas por um mínimo de dois até cinco pesquisadores. Assim, pode-se supor que a implementação de um Programa de Orientação Profissional deve ser orientada por pelo menos um profissional de Psicologia que tenha conhecimento cientifico na referida área para assim poder dar suporte tanto aos profissionais que irão trabalhar no projeto quanto aos alunos nas suas dificuldades e necessidades.

Dos oito artigos analisados, três focaram o ensino médio, dois tiveram como foco a educação profissional (curso técnico), um se efetivou no universo de um curso prévestibular, outro objetivou a Orientação Profissional no âmbito do ensino superior e um focou alunos do nono ano do ensino regular em Portugal. Dessa forma, pode-se observar que o processo de Orientação Profissional se adequa ao atendimento de distintos estágios do desenvolvimento educacional dos indivíduos. Os estudos indicam que a inserção de 
Programas de Orientação Profissional ao longo do ensino médio, incluindo a fase do prévestibular e ensino profissionalizante, traz resultados efetivos.

Quanto à população atendida, os artigos relataram o trabalho com grupos grandes, um com 127 alunos e outro com 53 alunos, mas também obtiveram resultados aqueles com o atendimento de grupos menores, entre 10 e 18 alunos, com faixas etárias variando entre 15 anos e 19 anos. Assim, pode-se compreender que os programas trazem bons resultados quando aplicados em grupos menores, mas também surtem efeitos em grupos maiores de alunos.

Das técnicas que foram empregadas nos oito programas de Orientação Profissional analisados neste estudo, destacam-se o psicodrama com debates em grupo e produção de cartazes. Outro programa utilizou entrevistas preliminares, dinâmicas de integração, testes e atividades de autoconhecimento, atividades relacionadas ao conhecimento das profissões, pesquisas dos próprios orientandos. Dois programas focaram o atendimento psicológico para o desenvolvimento do autoconhecimento e conhecimento das profissões. Um dos programas se pautou pelo aconselhamento individual para estudantes do ensino superior. Outro programa foi conduzido a partir de uma oficina, que se constituiu de oito encontros semanais, com duração de duas horas cada, embasadas em um enfoque psicossocial. Podese concluir que as diversas técnicas utilizadas serviram ao propósito da Orientação Profissional de maneira efetiva, sendo que a sua adoção parece estar diretamente vinculada ao objetivo da população, faixa etária atendida e local encontrado para as dinâmicas.

Dos oito programas analisados, um utilizou oito sessões, três empregaram nove sessões, um usou 10 sessões e dois utilizaram 12 sessões para completar os objetivos pretendidos. A partir desses resultados, pode-se indicar que o número adequado de encontros pode ser estabelecido entre oito e 12, para que possam ser atendidos aos propósitos do programa com eficácia.

Em síntese, a partir da análise dos programas de OP descritos nos artigos analisados, podem-se identificar algumas características dos programas que devem ser levadas em conta para que políticas públicas possam contar com maior efetividade. Para realização de tais programas, as equipes devem contar com pelo menos um psicólogo capacitado. Os 
programas devem abranger estudantes de ensino médio que pretendam realizar uma formação superior ou ainda aqueles que buscam uma qualificação técnica para entrada imediata no mercado de trabalho; além disso, estudantes universitários podem ser atendidos em programas de reorientação profissional.

É indicado que os programas contem com a participação de pequenos grupos, entre 10 e 18 participantes, para que todos tenham oportunidade de se fazerem ouvir. As técnicas utilizadas podem ser diversificadas, contando com diferentes bases teóricas, o que reforça ainda mais a necessidade da presença de pelo menos um psicólogo na equipe, pois esse profissional conhece diversas técnicas que podem ser efetivas na realização de programas de OP, que devem contar com um número de sessões que varie entre oito e 12 .

Observou-se que houve a participação voluntária como característica comum em todos os programas avaliados, e também o interesse e participação dessa população, percebido pela sua assiduidade, pelo desenvolvimento do trabalho e também com os resultados obtidos no fim do processo.

\section{Discussão}

Levando em consideração que a legislação brasileira não privilegia a Orientação Profissional como prática para alunos da escola pública, e na ausência de políticas públicas de OP, este trabalho se propôs a analisar modelos de Programas de OP que possibilitam a articulação de políticas públicas de OP no Brasil, visto que a atualmente a OP é disponibilizada, na maioria das vezes, na rede particular de ensino.

Observou-se, nas pesquisas descritas neste trabalho, a importância da oferta da OP para os jovens que terão de fazer uma escolha profissional, pois a OP propicia, primeiramente, a reunião desse grupo específico de jovens e a seguir o diálogo sobre o tema em questão. Esses processos são fundamentais para possibilitar decisões conscientes. Segundo Sobrosa, Santos, Oliveira e Dias (2014), as mudanças que ocorrem com o término do ensino médio podem gerar dificuldades para a maior parte dos jovens, uma vez que muitos são os obstáculos encontrados, alguns culturais e econômicos, outros de ordem 
prática. Os jovens tentam um equilíbrio entre o que desejam e o que de fato são capazes de concretizar. Nesse contexto, o trabalho com grupos promove uma rica troca de experiências, a observação, análise do problema e a solução observada, compartilhada e advinda da vivência pelo grupo, oportuniza uma reavaliação de atitude e mudança pessoal, como reflexo da vivência grupal.

A literatura aponta que a OP pode contribuir para a escolha profissional, pois, conforme Melo-Silva et al. (2004), Silva (2010), Ribeiro (2003), a Orientação Profissional se constitui como uma ferramenta e auxílio nesse momento de entrada no mercado de trabalho, sendo mais ofertada na rede privada de ensino. Soares et al. (2007), Souza et al. (2009), Silva, (2010), Veriguine, Basso e Soares (2014) concordam acerca do objetivo de a OP ser o processo de escolha profissional, no qual o indivíduo faz a análise da sociedade e do trabalho. É consenso entre esses autores que a OP não deve ser vista com o objetivo de atender apenas às classes mais favorecidas financeiramente; por isso, a introdução da OP em escolas públicas pode oferecer a todos os estudantes a possibilidade de discutirem a sociedade, escolha profissional e a entrada no mundo do trabalho. Observam ainda que a OP contribui para o questionamento de informações sobre as profissões, estudo e trabalho e nos fatores que determinam as suas escolhas (Tetu et al., 2011).

A OP parece ser uma possibilidade de melhoria na vida dos estudantes, diante das várias mudanças e situações novas, como o término do ensino médio e a indecisão do caminho a seguir. Consoante observam Sobrosa et al. (2014), os jovens anseiam pela OP que Ihes possibilite uma mais rápida e assertiva entrada na vida profissional, contrariando o modelo vigente de atendimento com OP apenas para os vestibulandos. Existe consenso entre os autores de que esse processo de escolha e decisão traz muito estresse, medo e insegurança. Moura e Silveira (2002), Moura et al. (2005) e Teixeira e Calado (2010) destacam a importância do desenvolvimento de programas e dos projetos de OP, visando à escolha da profissão e a inserção no mercado de trabalho e trazendo contribuição para os estudantes, ao auxiliar no processo de seu autoconhecimento e na elaboração de seus projetos de vida, como os projetos profissionais. 
Soares et al. (2007) e Tetu et al. (2011) consideram a importância do acesso a um Programa OP que possa facilitar o processo de escolha profissional, tendo capacidade de auxiliar o indivíduo na compreensão de seu próprio momento de vida, considerando sempre os aspectos pessoais, familiares, sociais, profissionais e econômicos. Nos estudos analisados, os jovens se confrontam com obstáculos impostos por diversas situações na sua entrada no mercado de trabalho, e a OP pode facilitar essa escolha, como enfatizam Moura e Silveira (2002), Moura et al. (2005), Soares et al. (2007) e Tetu et al. (2011).

Os jovens precisam tomar uma decisão entre a continuidade dos estudos, seja pela opção de um estudo técnico, superior, seja a interrupção destes e a entrada no mercado de trabalho, pela necessidade de se manter financeiramente e, em muitos casos, também pela exigência de contribuir financeiramente para a renda familiar. Há ainda a opção de manter ambos, estudo e trabalho. A sociedade atual passa por um processo de grande mudança, envolvendo novidades científicas e desenvolvimento de tecnologias, que descortinam um caminho que segue na trilha do aparecimento de novas profissões no mercado de trabalho. Isso traz aos jovens mais expectativas e incertezas na hora de fazerem suas escolhas, em uma etapa de vida na qual está se constituindo sua identidade, o que torna ainda mais difícil seu ingresso no mercado de trabalho. Muitas vezes sentem-se pressionados, pois sua decisão tem de levar à realização profissional, ao sentimento de utilidade à sociedade, em que os profissionais cada vez mais querem ser melhores no que fazem (Moura et al., 2005; Moura \& Silveira, 2002; Souza et al., 2009; Teixeira \& Calado, 2010; Tetu et al., 2011)

Tetu et al. (2011) e Soares et al. (2007) destacam que o jovem faz sua escolha profissional no momento que está tentando encontrar sua identidade, por meio da própria percepção de suas qualidades, preferências, aspirações, interesses e motivações. E a OP pode dar oportunidade a esse indivíduo de acessar meios e recursos que possam tornar mais fácil sua própria compreensão dessa fase de vida, quando questões pessoais, familiares, sociais e econômicas os direcionam para a escolha em seus estudos e ou as profissionais, para alcançar trabalho e realização pessoal. Lima e Fraga (2010) destacam que o processo de construção da identidade dos indivíduos se desenvolve de dentro para fora e que essa identidade é construída a partir do seu próprio pensamento. 
Já no processo de OP, e consequente desenvolvimento de uma carreira, esse indivíduo precisa ser avaliado globalmente, sua trajetória de vida fazendo parte desse processo. Soares et al. (2007), Tetu et al. (2011) e Oliveira e Neiva (2013) veem a necessidade de discutir as dificuldades do processo de escolha profissional, do curso superior e o de desenvolver um projeto de vida. Os fatores que envolvem a escolha profissional, aspectos pessoais e os sentimentos de angústia, medo e sofrimento desse processo, especialmente quando se aproxima o vestibular. É importante que o jovem possa contar nesse momento com o apoio dos pais, educadores e orientadores profissionais. Deve-se encarar essa escolha como um processo de crescimento individual, associado ao conhecimento das profissões e atividades profissionais, para sua inclusão na sociedade. Esse momento, na maioria das vezes, é determinado ou agravado pela condição financeira precária desse jovem, que, quase sempre, não foi preparado para o trabalho profissional e, consequentemente, não tem uma renda imediata que possa mantê-lo. É assim que a maioria desses jovens se encontra no fim do ensino médio, vivenciando esse conflito.

Existe consenso entre os autores que esse processo de escolha e decisão traz muito estresse, medo e insegurança. Moura e Silveira (2002) e Oliveira e Neiva (2013) indicam que a decisão profissional nem sempre é uma decisão madura e consciente, com critérios baseados no conhecimento de si mesmo e da realidade da profissão que o sujeito pretende seguir. Assim, o indivíduo muitas vezes toma uma decisão sem ter consciência das influências que o meio exerce sobre ele e sem ter informações dessa profissão. Pode-se perceber que a participação ativa e voluntária nos programas de OP analisados demonstrou que os participantes podem se tornar mais comprometidos com a escolha da sua profissão e do seu projeto de vida, obtendo maior clareza na escolha entre estudo e trabalho, e saindo do processo mais fortalecido em seus objetivos pessoais.

Observa-se, nos resultados dos programas analisados, que a implementação de Programas de OP em escolas do ensino médio, cursos profissionalizantes e cursos técnicos parece promissora para que se desenvolva uma maneira efetiva de compreender, atender e esclarecer às demandas desses jovens, gerando reflexos no âmbito educacional nacional. 
Para a consolidação desse processo, destaca-se a importância da existência das políticas públicas voltadas à OP.

\section{Considerações finais}

Tendo em conta que a legislação brasileira não privilegia a OP como prática para alunos da escola pública, e na ausência de leis que regulamentem ou possibilitem a realização de OP com essa população, buscou-se analisar programas de OP realizados por pesquisadores e relatados em artigos científicos de circulação nacional. O objetivo de tal análise foi identificar características desses programas que possibilitam a articulação de políticas públicas de OP que apresentem maior chance de efetividade, pois teriam por base programas que obtiveram êxito. Para tanto, os estudos foram agrupados e suas características foram identificadas.

Os resultados deste estudo podem contribuir ao elencar uma série de características desses programas que podem colaborar para o êxito da OP. As políticas públicas podem considerar tais diretrizes, mas é importante ter em conta que na realização desta pesquisa foram considerados apenas programas descritos em artigos científicos, e não foram contemplados outros tipos de trabalhos, como teses, dissertações, livros, publicações em congressos da área, entre outros, que poderiam contribuir com maior número de informações para maior efetividade no estabelecimento de tais políticas.

É importante considerar que a OP assume um papel de acolhimento e pode se constituir como mais um caminho para auxiliar os jovens a escolherem uma profissão e entenderem as suas possibilidades. Com a tomada de decisão quanto ao seu futuro profissional ocorrendo cada vez mais cedo, e diante de dúvidas e inseguranças, é provável que esses indivíduos necessitem de atenção e recursos, para que possam avançar em seus projetos de vida. Percebeu-se pelos estudos analisados que existe uma preocupação de orientar mais cedo os jovens, na própria escola, mas a legislação não acompanhou tal necessidade. 
Destaca-se a importância de a escolha ser problematizada, pois nesse período os jovens se veem tomados por diversos sentimentos, como ansiedades, incertezas e preocupações. Observou-se que as práticas de OP narradas neste estudo estão sendo realizadas por meio de trabalhos com grupos, focando em suas dúvidas e buscando auxiliar o jovem no autoconhecimento, conhecimento dos cursos e possibilidades de emprego, para uma escolha mais consciente.

Assim, o desenvolvimento desta pesquisa indicou a necessidade de realização de mais estudos que possibilitem uma melhor compreensão do processo de escolha profissional, e que levem em conta outras possibilidades, além do curso superior, como a entrada no mercado de trabalho. Entre essas escolhas, a realização de cursos técnicos voltados para uma atuação mais focada e imediata também pode ser considerada, pois tais estudos ajudariam a compreender como ocorre a construção dos projetos de vida desses jovens.

A falta de orientação profissional e de carreira pode interferir no projeto de vida dos jovens. Isso pode se manifestar em questões como sentimento de abandono, insucesso escolar, desemprego e certa descrença do jovem em relação à educação, podendo contribuir e motivar a evasão escolar, em especial às vivenciados por grupos sociais com níveis de qualificações mais baixos.

Este trabalho pretendeu favorecer a ocorrência de debates na educação e colaborar com a apresentação da necessidade de se elaborar políticas públicas de OP que levem em consideração o desenvolvimento de carreira, possibilitando a sua efetiva contribuição, tanto na escola pública como na escola particular.

\section{Referências}

Ambiel, R. A. M., Barros, L. O., Pereira, E. C., Tofoli, L., \& Bacan, A. (2017). Avaliação de Processos de Orientação Profissional e de Carreira: problemas e possibilidades. Avaliação Psicológica, 16(2), $128-136$. doi: http://dx.doi.org/10.15689/AP.2017.1602.02. 
Bonadiman, M. D., Scaff, L. A., Bardagi, M. P., \& Luna, I. N. (2016). Perfil dos usuários do Liop - Laboratório de Informação e Orientação Profissional da UFSC: mudanças observadas nos últimos anos. Caminho Aberto - Revista de Extensão do IFSC, 1(3), $91-100$.

Lei n. 9.394, de 20 de dezembro de 1996. (1996). Estabelece as Diretrizes e Bases da $\begin{array}{llll}\text { Educação. } & \text { Brasília, } & \text { DF. }\end{array}$ http://www.planalto.gov.br/ccivil_03/leis/19394.htm.

Cunha, E. P., \& Cunha, E. S. M. (2008). Políticas públicas sociais. In A. Carvalho, F. Salles, M. Guimarães \& W. Ude (Eds.). Políticas Públicas (pp. 11-26). Belo Horizonte: UFMG, Proex.

Fiorini, M. C., Bardagi, M. P., \& Silva, N. (2016). Adaptabilidade de carreira: paradigmas do conceito no mundo do trabalho contemporâneo. Revista Psicologia Organizações e Trabalho, 16(3), 236-247. doi: http://dx.doi.org/10.17652/rpot/2016.3.676.

Lima, R., \& Fraga, S. (2010). Intervir para ajudar e ajudar para construir: um modelo de intervenção psicológica com estudantes do ensino superior. Revista Brasileira de Orientação Profissional, 1 1(2), 269-277.

Melo-Silva, L. L., Lassance, M. C. P., \& Soares, D. H. P. (2004). A orientação profissional no contexto da educação e trabalho. Revista Brasileira de Orientação Profissional, 5(2), $31-52$.

Moura, M. R. (2014). Orientação Profissional para jovens de baixa renda. Dissertação de mestrado, Universidade Federal da Bahia, Salvador.

Moura, C. B., Sampaio, A. C. P., Gemelli, K. R., Rodrigues, L. D., \& Menezes, M. V. (2005). Avaliação de um programa comportamental de Orientação Profissional para adolescentes. Revista Brasileira de Orientação Profissional, 6(1), 25-40. doi: http://dx.doi.org/10.1590/S0103-166X2002000100001. 
Moura, C. B., \& Silveira, J. M. (2002). Orientação profissional sob o enfoque da análise do comportamento: avaliação de uma experiência. Estudos de Psicologia (Campinas), $19(1), 5-14$.

Oliveira, C. M. R., \& Neiva, K. M. C. (2013). Orientação Vocacional/Profissional: avaliação de um projeto piloto para estudantes da educação profissional. Revista Brasileira de Orientação Profissional, 14(1), 133-143.

Ribeiro, M. A. (2003). Demandas em orientação profissional: um estudo exploratório em escolas públicas. Revista Brasileira de Orientação Profissional, 4(1-2), 141-151.

Silva, F. F. (2010). Construção de projetos profissionais e redução da vulnerabilidade social: subsídios para políticas públicas de orientação profissional no ensino médio. Tese de doutorado, Universidade de São Paulo, São Paulo.

Silva, S., \& Bardagi, M. P. (2016). Intervenções de carreira do ensino superior: estrutura dos serviços na Grande Florianópolis. Rev. Psicologia em Foco, 8(12), 14-32.

Silveira, A. F., Cobalchini, C. C. B., Menz, D. M., Valle, G. A., \& Barbarini, N. B. (2007). Caderno de Psicologia e políticas públicas. Curitiba: Gráfica e Editora Unificado.

Soares, D. H. P., Krawulski, E., Dias, M. S. d. L., \& D’Avila, G. T. (2007). Orientação Profissional em contexto coletivo: uma experiência em pré-vestibular popular. Psicologia: Ciência e Profissão, 27(4), 746-759. doi: http://dx.doi.org/10.1590/S1414-98932007000400014.

Sobrosa, G. M. R., Santos, A. S., Oliveira, C. T., \& Dias, A. C. G. (2014). Perspectivas de futuro profissional para jovens provenientes de classes socioeconômicas desfavorecidas. Temas em Psicologia, 22(1), 223-234. doi: http://dx.doi.org/10.9788/TP2014.1-17. 
Souza, L. G. S., Menandro, M. C. S., Bertollo, M., \& Rolke, R. K. (2009). Oficina de Orientação Profissional em uma escola pública: uma abordagem psicossocial. Psicologia: Ciência e Profissão, 29(2), 416-427.

Teixeira, M. O., \& Calado, I. (2010). Avaliação de um programa de educação para a carreira: um projecto de natureza exploratória. Revista Brasileira de Orientação Profissional, $17(2), 213-218$.

Tetu, V., Domingues, A. S., Chiochetta, L., \& Veloso, M. M. (2011). O trabalho de Orientação Profissional com um grupo de alunos do $3^{\circ}$ ano do ensino médio. I Seminário Internacional de Representações Sociais, Subjetividade e educação - SIRSSE, 1230912316.

Veriguine, N. R., Basso, C., \& Soares, D. H. P. (2014). Juventude e perspectivas de futuro: a Orientação Profissional no Programa Primeiro Emprego. Psicologia: Ciência e Profissão, 34(4), 1032-1044. doi: http://dx.doi.org/10.1590/1982-370000902013.

Recebido em: 7/6/2018

Aprovado em: 7/2/2019 